\title{
Familial Hashimoto's thyroiditis with kidney impairment
}

\author{
A SHUPER, T LEATHEM, A PERTZELAN, B EISENSTEIN, AND M MIMOUNI \\ Department of Paediatrics B, Institute of Paediatric Endocrinology, and Paediatric Nephrology Unit, \\ Beilinson Medical Centre, Petah Tikva, Israel, and the Middlesex Hospital Medical School, London, \\ England
}

SUMmary A 12 year old boy and his two sisters with Hashimoto's thyroiditis and renal impairment were studied. Three generations of this family had autoimmune thyroid disease: Graves' disease was diagnosed in the first generation, and the second and third generations had thyroid enlargement with abnormal thyroid function and immunological abnormalities. The disease in this family could not be explained simply by the types of human leucocyte antigens found. Renal disease in autoimmune thyroid disease is uncommon, treatment difficult, and the prognosis unknown.

The proteinuria disappeared in all three children during the three and a half years of follow up, which implies that the renal impairment may be transitory in some patients.

There are five autoimmune thyroid diseases: Hashimoto's thyroiditis, primary myxoedema, non-toxic goitre with detectable thyroid growth stimulating immunoglobulins, Graves' disease, and ophthalmic Graves' disease. ${ }^{1-5}$ These diseases commonly run in families, and relatives of patients with autoimmune thyroid disease often have an increased prevalence of antithyroid antibodies. ${ }^{67}$ These patients may also have circulating immune complexes with thyroglobulin and antithyroglobulin. ${ }^{89}$ In a few patients kidney damage and nephrotic syndromes have been reported.

We describe a family in which autoimmune thyroid diseases were found in three generations, with a variety of autoimmune abnormalities and evidence of immune complex nephritis. The course of the kidney diseases in these patients may imply that kidney impairment in autoimmune thyroid diseases is transitory, though a longer period of follow up is needed to confirm this.

\section{Details of family}

The propositus was referred to the outpatient clinic of the Department of Paediatrics B at the age of 11 years 9 months because of neck swelling for the past two months. The only abnormality found on physical examination was a large goitre (Table 1). Height and weight were on the 75th centile, and pubertal stage was Tanner's stage II. ${ }^{10}$ Pertinent laboratory

Table 1 Evaluation of thyroid function and results of urine analysis at first examination

\begin{tabular}{|c|c|c|c|c|c|}
\hline & \multirow[t]{2}{*}{ Goitre grading" } & \multirow{2}{*}{$\begin{array}{l}\text { Free } \\
\text { thyroxime } \\
(\text { pmol/l) }\end{array}$} & \multirow{2}{*}{$\begin{array}{l}\text { Total } \\
\text { triiodothyromine } \\
\text { (nmol/l) }\end{array}$} & \multicolumn{2}{|c|}{ Thyrotrophic hormone (mU/l) } \\
\hline & & & & Basal & $\begin{array}{l}\text { Peak (after intravenous bolus } \\
\text { of } I 00 \mathrm{\mu g} / \mathrm{m}^{2} \text { thyrotrophin } \\
\text { releasing hormone) }\end{array}$ \\
\hline Father (II-3) & Easily palpablc & $23 \cdot 2$ & $2 \cdot 16$ & $4 \cdot 2$ & $14 \cdot 0$ \\
\hline Mother (II-4) & Easily palpable & $18 \cdot 0$ & 1.69 & $2 \cdot 8$ & $19 \cdot 0$ \\
\hline \multicolumn{6}{|l|}{ Siblings: } \\
\hline III-2 (propositus) & Grade 4 & $15 \cdot 4$ & 1.54 & 23.8 & $1(x) \cdot 0$ \\
\hline III-3 & Grade 3 & $23 \cdot 2$ & $3 \cdot 08$ & $11 \cdot 6$ & $23 \cdot 0$ \\
\hline $\mathrm{III} \cdot 4$ & Grade 2.5 & $21 \cdot 9$ & $2 \cdot 62$ & $6 \cdot 5$ & $16 \cdot 1$ \\
\hline
\end{tabular}

Normal values: free thyroxine $8-29 \mathrm{pmol} / \mathrm{l}$; total tri-iodothyronine: $1.54-3.08 \mathrm{nmol} / \mathrm{l}$; thyroid stimulating hormone $<6 \mathrm{mU} / \mathrm{l}$. 


\section{Shuper, Leathem, Pertzelan, Eisenstein, and Mimouni}

data are summarised in Table 1 and are compatible with the diagnosis of latent hypothyroidism. Histological examination of a needle biopsy specimen of the gland confirmed the diagnosis of Hashimoto's thyroiditis, and treatment with thyroxine sodium $100 \mu \mathrm{g}$ daily was started.

Six months after his first visit he had puffy eyes and pitting oedema of the legs and had gained a lot of weight. Haematological investigations showed an erythrocyte sedimentation rate of $106 \mathrm{~mm}$ in the first hour, a white cell count of $7 \cdot 6 \times 10^{9} / 1$, a haemoglobin concentration of $1.55 \mathrm{mmol} / \mathrm{l}$, and a platelet count of $440 \times 10^{9} / 1$ (the differential was normal). Biochemical investigations showed a urea nitrogen concentration of $4.6 \mathrm{mmol} / \mathrm{l}$, creatinine concentration of 39.8 $\mu \mathrm{mol} / \mathrm{l}$, potassium concentration of $4.3 \mathrm{mmol} / \mathrm{l}$, sodium concentration of $142 \mathrm{mmol} / \mathrm{l}$, chlorine concentration of $107 \mathrm{mmol} / \mathrm{l}$, calcium concentration of $1.9 \mathrm{mmol} / \mathrm{l}$, and phosphorus concentration of 1.68 $\mathrm{mmol} / \mathrm{l}$. Total protein concentration was $53 \mathrm{~g} / \mathrm{l}$, that of albumin being $23 \mathrm{~g} / \mathrm{l}$. Cholesterol concentration was $9.06 \mathrm{mmol} / \mathrm{l}$, with total lipids of $7.5 \mathrm{~g} / \mathrm{l}$ and triglycerides of $2.75 \mathrm{mmol} / \mathrm{l}$. Repeated analysis of his urine showed obvious proteinuria $(>230 \mathrm{mg} /$ hour $/ \mathrm{m}^{2}$ ) but no haematuria. Because these findings suggested a nephrotic syndrome renal biopsy was performed. On histological examination there was irregular thickening of the glomerular capillary walls with epimembranous hyaline depositis and endocapillary hypercellularity, which suggested a mixed membranous and proliferative glomerulonephritis. Studies of the renal biopsy specimen with immunofluoresence and immunoperoxidase staining showed glomerular capillary clumps of thyroglobulin, IgG, IgM, C3, and kappa and lambda chains of comparable distribution.

Treatment was begun with cyclophosphamide $125 \mathrm{mg}$ daily for eight weeks and prednisone $60 \mathrm{mg}$ daily for four weeks, the prednisone to be reduced gradually to $40 \mathrm{mg}$ every other day. At that time thyroxine sodium was stopped. The child was followed up for one year after this regimen was started. During this period the goitre, which had become smaller during the treatment with thyroxine sodium, enlarged; the concentration of thyroid stimulating hormone, which had dropped to 3.6 $\mathrm{mU} / \mathrm{l}$, rose to the pretreatment value of $60 \mathrm{mU} / \mathrm{l}$. Treatment with thyroxine sodium was therefore started again. After this treatment started the concentration of protein in his urine slowly but progressively reduced, and 18 months later it had dropped to $85 \mathrm{mg} / \mathrm{hour} / \mathrm{m}^{2}$; after six further months it was down to $32 \mathrm{mg} / \mathrm{hour} / \mathrm{m}^{2}$. After two and a half years of treatment the proteinuria had disappeared. During this period concentrations of antithyroid antibodies, both antimicrosomal and antithyroglo- bulin, decreased to a constant titre of $1 / 80$ to $1 / 160$. At $15 \frac{1}{2}$ years old the child had a small goitre, but otherwise physical examination showed no abnormality and his growth and pubertal stage were appropriate for his age.

Three generations of the family were examined (Figure); all were of Ashkenazi-European origin. Seven subjects (I-1, 3, 4, and II-1, 2, 5, 6) were apparently healthy with no clinical evidence of thyroid dysfunction; no laboratory investigations were performed in these subjects. Other siblings of subject I-4 had died in the holocaust. The child's paternal grandmother (I-2) had had Graves' disease for the past 10 years; she was being treated with methimazole and was euthyroid when examined. One of the maternal grandmother's sisters (I-5) also had Graves' disease. She had undergone subtotal thyroidectomy 20 years previously and was not taking any antithyroid drugs. The parents of the propositus (II-3, 4) both 36 years old and unrelated, were thought to be in good health; on examination, however, their thyroid glands were mildly enlarged. No other findings suggestive of altered thyroid function were found. Pertinent data on them are summarised in Tables 1,2, and 3. Results of haematological investigations and urine analysis and blood glucose concentrations were normal in the parents.

The propositus had three sisters (III-1, 3, 4), who were aged 12 years 9 months, 9 years 3 months, and 6 years when first examined. They all had similar 'neck swellings', which had appeared at about the same time as that of the propositus. Their medical history was unremarkable. Table 1 shows their goitre grading. ${ }^{11}$ The eldest sister (III-1) had a mild

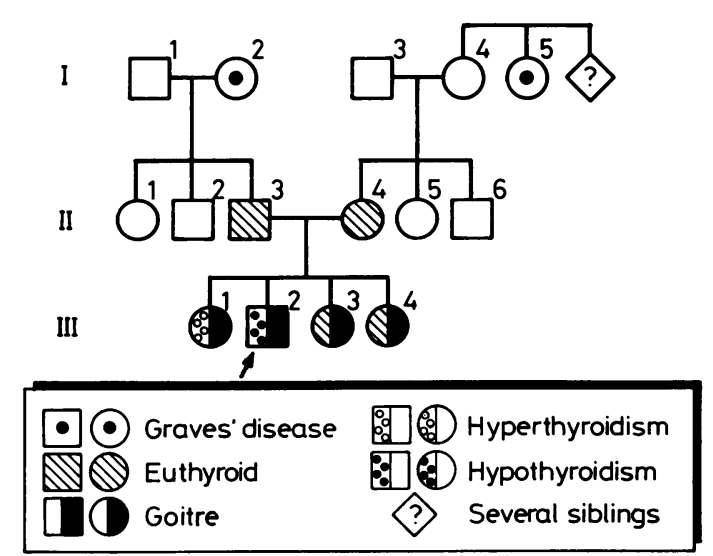

Figure Pedigree of family with autoimmune thyroid disease and kidney impairment. 
Table 2 Immunological investigations at first evaluation (1983) and 18 months later (1984)

\begin{tabular}{|c|c|c|c|c|c|c|c|c|c|c|c|c|}
\hline & \multicolumn{4}{|c|}{ Thyroid } & \multicolumn{2}{|c|}{$\begin{array}{l}\text { Stomach } \\
\text { antiparietal cells }\end{array}$} & \multirow{2}{*}{\multicolumn{2}{|c|}{$\begin{array}{l}\text { Antinuclear } \\
\text { antibodies }\end{array}$}} & \multirow{2}{*}{\multicolumn{2}{|c|}{$\begin{array}{l}\text { Circulating immune } \\
\text { complexes } \\
\text { (PEG method) }\end{array}$}} & \multicolumn{2}{|c|}{$\begin{array}{l}\text { Proteinuria } \\
\left(\mathrm{mg} / \text { hour } / \mathrm{m}^{2}\right)\end{array}$} \\
\hline & \multicolumn{2}{|c|}{ Antithyroglobulin } & \multicolumn{2}{|c|}{ Antimicrosomal } & \multirow{2}{*}{1983} & \multirow{2}{*}{1984} & & & & & \multirow{2}{*}{1983} & \multirow{2}{*}{1984} \\
\hline & 1983 & 1984 & 1983 & 1984 & & & 1983 & 1984 & 198.3 & 1984 & & \\
\hline Father & - & - & 400 & 400 & + & + & - & - & 116 & 59 & Neg & Neg \\
\hline Mother & 80 & 80 & 400 & 400 & + & + & 20 & 10 & 65 & 45 & $\mathrm{Neg}$ & $\mathrm{Neg}$ \\
\hline \multicolumn{13}{|l|}{ Siblings: } \\
\hline III-1 & 640 & 1280 & 400 & 1600 & - & - & - & 40 & 124 & 49 & $13 \cdot 4$ & $9 \cdot 4$ \\
\hline IIl·2 (propositus) & 1280 & $100(0)$ & 1600 & 1600 & - & - & - & - & 72 & 41 & 230 & 85 \\
\hline III-3 & 40 & 160 & 100 & 100 & - & - & - & - & 215 & 85 & $10 \cdot 8$ & Neg \\
\hline III-4 & - & 160 & - & 1600 & - & - & - & - & 104 & 59 & Neg & Neg \\
\hline
\end{tabular}

Normal values for circulating immune complexes: $100 \mu \mathrm{g}$ IgG equivalent ml.

Reciprocal titres obtained by haemagglutination with Wellcome Thymune kits.

Table 3 Human leucocyte antigen haplotypes

\begin{tabular}{lrll}
\hline & $H L A-A$ & $H L A-B$ & HLA-DR \\
\hline Grandmother (I-2) & $28 / 29$ & $14 / 7$ & $6 / 2$ \\
Aunt (I-5) & $26 / 26$ & $35 / 17$ & $4 / 5$ \\
Father (II-3) & $2 / 29$ & $14 / 7$ & $7 / 2$ \\
Mother (II-4) & $24 / 28$ & $14 / 14$ & $5 / 1$ \\
Siblings: & & & \\
III-1 & $2 / 28$ & $14 / 14$ & $7 / 1$ \\
III-2 (propositus) & $2 / 24$ & $14 / 14$ & $7 / 5$ \\
III/3 & $2 / 24$ & $14 / 14$ & $7 / 5$ \\
III-4 & $29 / 28$ & $7 / 14$ & $2 / 1$ \\
\hline
\end{tabular}

tremor. The results of investigations suggested that she had hyperthyroidism, and she was given prophylthiouracil $200 \mathrm{mg}$ a day, which was gradually reduced as function of the hypophyseal axis improved (shown by repeated estimation of thyrotrophin releasing hormone concentrations). Proteinuria of $9.4-13.4 \mathrm{mg} / \mathrm{hour} / \mathrm{m}^{2}$ was found, but there was no other clinical or laboratory evidence of nephrotic syndrome. The proteinuria remained within this range after the antithyroid drugs had been stopped, but one and a half years later no protein could be found in the urine. Physical examination of the two other sisters showed no obvious abnormality. One (III-3) had a slightly increased basal concentration of thyroid stimulating hormone which later returned to normal. Repeated urine analysis showed a proteinuria of $10 \cdot 8 / \mathrm{hour} / \mathrm{m}^{2}$, but this disappeared spontaneously within several months. The initial laboratory investigations of the other sister (III-4) all yielded normal results. Table 2 summarises the immunological data on the family, and the human leucocyte antigen haptotypes are shown in Table 3 . Renal biopsies were not performed for two of the sisters (III-1 or III-3).

\section{Discussion}

In this family evidence of autoimmune thyroid disease was found in three generations. Graves' disease was diagnosed (in another hospital) in two patients of the first generation; in the second generation slightly enlarged thyroid glands were found in two patients, as well as mildly raised titres of autoantibodies against thyroid, stomach, and nuclei. In the third generation the children had goitres and autoantibodies as well as increased concentrations of circulating immune complexes, but the clinical manifestations differed and included hyperthyroidism, latent hyperthyroidism, and euthyroidism.

The occurrence of Graves' disease and Hashimoto's thyroiditis in the same family and the increased prevalence of autoantibodies in relatives of patients with Hashimoto's thyroiditis are well documented, ${ }^{67}$ as are the occurrence of Hashimoto's thyroiditis in a parent and offspring, in twins, and in triplets. ${ }^{12}$ Such an extensive distribution of autoimmune thyroid diseases in one sibship, however, with such variability in the clinical and immunological presentations, is unusual. Both parents had evidence of autoimmune thyroid disease; the mother's haplotype included $D R_{5}$, which is associated with Hashimoto's thyroiditis. ${ }^{13} \mathrm{I}^{14}$ The presence of this antigen, however, can explain the symptoms of only two of the children (III-2 and 3 ) and not of the other two (III-1 and 4). None of the haplotypes of either of the women with Graves' disease (I-2 and I-5) was transmitted to generation III. HLA B14, which is frequently found in Israelis, was present in all the affected family members except one (I-5). B14 has not, however, been reported previously in association with Hashimoto's thyroiditis. It is possible that on both sides of this family there was a predisposition to the immunological defect that is responsible for Hashimoto's thyroiditis, and that this was transmitted vertically to the third generation. Because of the synchronous appearance of the goitre in the siblings it may also 
be that a common event such as a viral infection triggered the autoimmune mechanism in the children, and possibly in the parents as well.

The association of immune complex nephritis with Hashimoto's thyroiditis as in the propositus is rare. ${ }^{9}$ 13-18 Membranoproliferative glomerulonephritis with the deposition of immune complexes with thyroglobulin as the antigen was reported in these patients. In one case thyroglobulin was also shown in the circulating immune complexes, with a positive correlation between the serum concentrations of these complexes and the severity of the disease. ${ }^{9}$ It was suggested that the glomerular disease was caused by trapping of nephritogenic immune complexes from the blood stream. In our propositus thyroglobulin was found in the glomerular capillary clumps but not in the circulating immune complexes. Glomerular deposits are formed in situ by the reaction of free antibody with a fixed antigenic constituent of the glomerular capillary wall. ${ }^{19}$ Proteinuria alone, without the nephrotic syndrome, has been reported in two of 27 patients with Hashimoto's thyroiditis, ${ }^{20}$ but the natural course of this type of kidney disease is unknown. Some patients with kidney disease underwent total thyroidectomy with the aim of eliminating the antigen. In these cases the proteinuria was not eliminated during a follow up course of several months ${ }^{13} 16$ but the circulating antimicrosomal and antithyroglobulin antibodies disappeared. ${ }^{16}$ Our patients have now been followed up for three and a half years. None of these three children with renal impairment had proteinuria when last seen. Although this is after a short term follow up, it may indicate either that thyroidectomy should not be performed in all patients or that it should not be done in the early stages of the disease. Interestingly, in some patients with Graves' disease the immune complex glomerulonephritis was associated with the antithyroid treatment, ${ }^{1421}$ either radioiodine or drugs. Whether such treatment has a role in the kidney disease or whether the association is coincidental is unknown.

Physicians must be aware of the possibility of impairment of the kidneys in autoimmune thyroid diseases and of the importance of doing repeated urine analyses. Only through better diagnostic accuracy can management and prognosis of these patients be improved.

We thank Professor D Doniach of the Middlesex Hospital, London, and Dr H Stark of the Beilinson Medical Centre, Petah Tikva, for their help in the investigation and treatment of these patients.

\section{References}

1 Doniach D, Chiovato L, Hanafusa T, Bottazzo GF. The implication of thyroid growth immunoglobulins (TGI) for the understanding of sporadic non-toxic nodular goitre. Springer Semin Immunopathol 1982;5:433-46.

2 Doniach D. Bottazzo GF, Russell RCG. Goitrous autoimmune thyroiditis (Hashimoto's disease). Clin Endocrinol Metab 1979;8:63-80.

3 Doniach D. Humoral and genetic aspects of thyroid autoimmunity. Clin Endocrinol Metab 1975:4:267-85.

4 Kidd A. Okita N. Row VV, Volpe R. Immunologic aspects of Graves' and Hashimoto's diseases. Metabolism 1980;29:80-99.

5 Doniach D. Hashimoto's thyroiditis and primary myxoedma viewed as separate entities. Eur J Clin Invest 1981;11:245-7.

${ }^{6}$ Roitt IM, Doniach D. Reassessment of studies on the aggregation of thyroid autoimmunity in families of thyroiditis patients. Clin Exp Immunol 1967:2(suppl):727-36.

7 Burek LC, Hoffman WH, Rose NE. The presence of thyroid autoantibodies in children and adolescents with autoimmune thyroid disease and their siblings and parents. Clin Immunol Immunopathol 1982;25:395-404.

${ }^{8}$ Calder EA, Irvine WJ. Cell mediated immunity and immune complexes in thyroid disease. Clin Endocrinol Metab 1975:4:287-318.

" Jordan SC, Buckingham B, Saka R, Olson D. Studies of immune complex glomerulonephritis mediated by human thyroglobulin. N Engl J Med 1981;304:1212-5.

11 Tanner JM. Whitchouse RH. Longitudinal standards for height, weight, height velocity, and stages of puberty. Arch Dis Child 1979:51:170-9.

"Shichijo K. Clinical study of thyroid gland. Journal of the Japanese Society of Internal Medicine 1985:46:1229. (Cited by Sato T, Takota I, Taketain T, Saiola K. Nakojima H. Concurrence of Graves' disease and Hashimoto's thyroiditis. Arch Dis Child 1977;52:951-5.

12 McGregor AN. Roberts DT, Hall R. A study of triplets with Hashimoto's thyroiditis. Postgrad Med J 1979;55:894-6.

13 O'Regan S, Fong JSC, Kaplan BS, deChardarevian JP, Lapointe N. Drummond KN. Thyroid antigen-antibody nephritis. Clin Immunol Immunopathol 1976;6:341-6.

14 Ploth DW, Fitz A, Schnetzler D, Scidenfeld J, Wilson CB. Thyroglobulin-antithyroglobulin immune complex disease complicating radio-iodine therapy. Clin Immunol Immunopathol 1978;9:327-34

15 Jordan SC, Bukingham BA, Kogut MD, Fine RN. Immune complex glomerulonephritis (ICGN) mediated by thyroglobulin antigen-antibody. Kidney Int 1979;16:912.

is Horvath F. Teague P. Gaffney EF, Mars DR. Fuller TJ. Thyroid antigen associated immune complex glomerulonephritis in Graves' discase. Am J Med 1979;67:901-4.

17 Strakosch CR, Wenzel BE, Row VV, Wolpe R. Immunology of autoimmunc thyroid discases. $N$ Engl J Med 1982:307: $1499-1505$.

${ }^{18}$ Farid NR, Sampson L, Noens H, Barnard JM. The association of goitrous autoimmunc thyroiditis with HLA-DR5. Tissue Antigens 1981:17:265-8.

${ }^{19}$ Couser WC. What are circulating immune complexes doing in glomerulonephritis? N Engl J Med 1981:306:1230-1.

211 Churchill DN, David N. Proteinuria in Hashimoto's thyroiditis. N Engl J Med 1981:305:1286.

${ }^{21}$ Reynolds LR, Bhatheria D. Nephrotic syndrome associated with methimazole therapy. Arch Intern Med 1979:139:236-7.

Correspondence to Dr A Shuper, Department of Paediatrics B, Beilinson Medical Centre, Petah Tikva 49 100. Isracl.

Received 26 February 1987 